\title{
From inebriety to addiction: terminology and concepts in the UK, 1860-1930
}

\begin{abstract}
The aim of the research was to explore how key addiction terminology was used in medical publications in Britain between 1860 and 1930 exploiting the possibilities of digitised resources. Specifically, it sought to identify differences in use of concepts over time and between sources. It also sought to identify if quantitative research on digital resources confirmed conclusions drawn from well-known qualitative research.
\end{abstract}

Keyword searches were carried out in digitised specialist and general medical journals, and successive editions of medical textbooks, chosen to enable comparison with a cross-national European study.

We examined 1) First and total usage of terms in the focal period, by journal title; 2) Yearly, five-yearly or decadal usage of terms, by journal title.

We found that terms such as 'Habit', 'chronic poisoning', 'alcoholism', and 'addiction' were all used regularly in various contexts from 1860. References to 'inebriety' and 'dipsomania' started in the 1860s; 'morphinism' in the 1870s, and 'morphinism' and 'narcomania' in the 1880s, with similar trends observed between medical journals. Searches on combined terms further indicated that 'habit' and 'addiction' featured more in discussions of drugs, rather than alcohol.

The combined digital and standardised searches chiefly showed the rise and decline of 'inebriety' and of 'alcoholism' as terms, and the ascent of 'addiction' (applied to drugs only). Methodologically, the chosen approach allowed a clear and detailed picture of the historical use of selected terms, which confirmed existing conclusions but also added new dimensions such as the decline of 'alcoholism'. However, the digitised searches also raised a number of 
unanticipated problems, the implications of which are discussed and which should be considered before over enthusiastic use of such methods.

\section{Introduction}

The idea that excessive consumption of alcohol and drugs was a 'disease' to be managed by medical professionals and through treatment emerged in North America and Europe in the course of the nineteenth and early years of the twentieth century. The rise of disease theories in Britain and the United States has attracted particular study by historians and has been extensively analysed, using standard qualitative historical methodology. ${ }^{1}$ The terminology used to articulate such ideas was important both as a reflection of the emerging medical view of alcohol and drug use and as a way of shaping the response to these substances and the people that used them. Charting fluctuations in the language associated with drug and alcohol use is thus an important step in assessing the history of substance use. Moreover, as the terminology used also varied across national boundaries and within countries over time, examining the language of addiction is a useful tool for exploring temporal and spatial differences.

The extensive digitisation of historical source material in recent years offers new possibilities for the exploitation of historical data. In this study digitised British sources were analysed for a period when there was widespread discussion of disease ideas in relation to alcohol and drugs, and a content analysis was undertaken of other sources which had not been digitised. The results were then compared with the conclusions drawn from qualitative research methods which had been used to underpin the existing historiography. The analysis confirmed some of the conclusions from qualitative research but also highlighted differences, such as the divergence between the decline of 'alcoholism' and the rise of ' addiction', used 
as a term applied only to drugs. The quantitative study thus deepened existing analysis and pointed to trends which help explain the later histories of concepts applied to drugs and to alcohol. The research also drew attention to some of the limitations of digital resources, and counsels against over enthusiastic adoption of such methods.

\section{Historiography: overview}

Before analysing the results of this new form of research, let us set this work in the context of the existing historiography. There has been debate about the role of ideas of 'disease' in connection with drugs and alcohol during the late eighteenth and early nineteenth century. It used to be argued that a modern concept of 'addiction' developed or was 'discovered' in America towards the end of the eighteenth century. ${ }^{2}$ The American physician Benjamin Rush published his Inquiry in the Effects of Ardent Spirits on the Human Body and Mind in 1784. Thomas Trotter was an English counterpart, often also hailed as the originator of disease views of alcoholism. He published An Essay Medical, Philosophical and Chemical on Drunkenness and its Effects on the Human Body, in 1804. Trotter saw the habit of drunkenness as a 'disease of the mind' with a particular role for the medical profession. More recently this view of 'firsts' has been challenged and historians have pointed out that such discussions about disease and alcohol were also common in the eighteenth century among many other writers. In fact, the key features of the concept had been developed throughout that century and were more or less in place by the 1770 s. They were part of ongoing debates about the relationship between the body and the mind and about the moral implications of this dynamic. What was different about the late eighteenth century and early nineteenth century declarations of Rush and Trotter, so the historian Roy Porter has persuasively argued, was not the theories per se, but the fertile context in which these theories 
found themselves. Evangelical Christianity, the moral movement of temperance, the expanding ambitions of the state, all provided suitable ground for ideas of disease to take root. Porter argued that the social context made theories assume importance and significance. $^{3}$

The period we focussed on for our digital research (1860-1930) is already recognised in the secondary literature as one of great significance for the formation and establishment of ideas about disease applied to alcohol and drugs. Later in the nineteenth century a key concept in the British (and American) sphere was that of 'inebriety' covering both drink and drugs. It was connected with professional societies in both the US and the UK - the British Society for the Study and Cure of Inebriety was formed in $1884 .^{4}$ Here, the disease concept was being advanced as an alternative to criminalisation of the drinker, to the penal approach. Treatment in a hospital or inebriate asylum was to be actively promoted in opposition to confinement in prison. Three ideas dominated the Society's early work: advocacy of a disease view of inebriety as the scientific alternative to what was seen as an outmoded moralistic approach; medical concepts and approaches as an humane alternative to imprisonment; and the belief that the State and the medical profession should work together to achieve these ends. The Society's original optimism was shown in its title, although the 'cure' had been dropped by the end of the 1880s. In its advocacy of inebriates legislation, the Society encompassed drinking and drug taking (in liquid form in products such as laudanum) together.

The nineteenth century was also notable for a different, continental European, strand of thinking about disease which derived from theorising about insanity with a terminology of 'dipsomania', 'monomania', or 'chronic alcoholism'. The mixing of moral and medical also derived from concepts within the study of insanity, for example Prichard's concept of 'moral insanity', and were carried over to discussion of inebriety. ${ }^{5}$ 
But other concepts also came into play, in particular a specific way of theorising about drugs which explains a subsequent divergence in thinking. Ideas originated from European writers initially and were specifically focussed on the hypodermic injection of morphia and its effects. These technical developments led to a distinctive way of writing about the effects of drugs which did not fit within the 'inebriety' paradigm. Dr Edward Levinstein of Berlin was the first European writer whose work reached the British medical profession. He published Die Morphiumsucht nacht Eigenen Beobachtungen in German in 1877 and it was translated the following year as Morbid Craving for Morphia. ${ }^{6}$

Not all medical writers used this language. The leading British physician T.C. Allbutt's textbook Systems of Medicine, which went through many editions, used the terminology of 'opium poisoning' to which was added the words 'and other intoxications'. ${ }^{7}$ The texts which still used ideas about 'poisoning' would divide their discussion into two sections - 'acute poisoning' which was the result of overdose, accidental or otherwise, and what they called 'chronic poisoning' which was akin to 'habit' in other phraseology. This divergence was important because it linked medical ideas to those also common in pharmaceutical regulation. The language was much more neutral in tone than the moral/medical formulations which marked both inebriety and the emergent morphine discourse. It talked about managing a condition rather than treating a disease.

Increasingly, however, the language of a separate condition called 'addiction' was applied to drugs as a whole, and this was certainly in place by the outbreak of World War One. Medical writers talked about 'morphinomanias and inebriety' well into the 1900s, while Norman Kerr's standard text Inebriety, Its Etiology, Pathology, Treatment and Jurisprudence first published under that title in the late 1880s, was republished as Inebriety: or Narcomania in 1894. What was happening during the 1890s and early 1900s, slowly but surely, was the 
decline of inebriety and the emergence of a separate set of ideas about morphinomania or narcomania, applied to all opiate substances - but not to drink. By 1914, the language of 'addiction' was taking precedence and was seen as new. This was not just a semantic nicety but indicated a new modernism, what the historian Tim Hickman has called a cultural crisis of modernity, which ideas about addiction helped both to support and to create. ${ }^{8}$

\section{The Qualitative Picture}

Qualitative material for this period has already been used in the British secondary literature and conclusions drawn. So, in this study, for which the quantitative dimension was the main focus, we decided to examine one source in more detail in order to deepen the qualitative picture of these developments. Using the Proceedings of the Society for the Study of Inebriety later (from 1903), The British Journal of Inebriety, the initial dominance of the 'inebriety paradigm' and its relationship to debates about criminal justice and the drunkard, was clear. At a meeting of the Society for the Study of Inebriety in July 1884, Dr George Harley stressed the role of heredity, a key factor in these discussions.

'...hereditary insanity is due to the transmission from parent to child-not of abnormal thoughts, but of the morbid brain tissue itself in which the thoughts originate. In like manner, the drunkard does not transmit to his offspring the craving for alcohol, but the abnormal organic bodily tissue which gives rise to the craving.' 9

For Dr Norman Kerr, the President of the Society, summing up the debate, the implications of the tension between morality and disease was clear.

'All controversy, therefore, as to whether inebriety was a disease, a vice a crime, or a sin, seemed to him to be beside the question and of no practical value. The main point was to 
recognise the physical element of the abnormal alcoholised condition, and to treat that; while, at the same time, paying due attention to the mind, the spirit and the soul. ${ }^{10}$

The main aim of the Society's discussions in these early years was to establish a formal system of treatment separate from the criminal justice system. There was a strong connection with similar moves in the United States and the networks between the US and the UK were extensive. A. Oakey Hall, the ex mayor of New York, spoke to the Society at this time about the progress of legislation for the inebriate in his country. In the US, he argued, surprisingly in the light of later developments, there was a system of state medicine absent in the UK.

'When, therefore, the confirmed and will- powerless Inebriate became equally acknowledged to be a diseased person, it was simply in accordance with the public system that the state should provide him or her with a public Hospital or Retreat., ${ }^{11}$

This interest in the US continued throughout the early years of the Society and there were moves to put the resume of US legislation before the British Prime Minister and Home Secretary.

When Dr Joseph Parrish, President of the American Association for the Cure of Inebriety, visited the UK in 1885, the British Society drew the connections between the preventive role of temperance and the treatment focussed activities of the medical profession concerned with inebriety and disease. The meeting which welcomed Dr Parrish

'..while bidding God-speed to every intelligent endeavour by temperance and prohibitive agencies to prevent drunkenness, earnestly prays for the cooperation of all temperance reformers and philanthropists in America and Britain with enlightened medical treatment, in a united and sustained attempt at the rescue, reformation and cure of the pitiful victims of alcoholic indulgence.' 12 
In the pages of the Society's journal, the terminology of inebriety was strong at least until the outbreak of the First World War. The prime concern was with the nature of how this disease developed-was it inherited or acquired in some way? In Kerr's view the disease developed through a combination of emotional and physical brain changes. Giving his Presidential address to the Society in May 1887, he saw the craving for drink as probably dependent on functional changes in the brain, but these changes could only be sparked into life because of some further emotional defect, some want of will power which was transmitted from past generations. He stated that what was involved was

'...a deficient tonicity of the cerebral and central nervous system, with an ongoing defective inhibition.'

This could be either inherited or acquired.

'In a considerable proportion of cases of developed inebriety, the family history shows that the lack of self control was transmitted...Though alcohol is the commonest cause of this hereditary defect, yet lack of sufficient brain will and restraining power may be handed down by parents who have never tasted an alcoholic or other inebriant.

The pathological depravity of the cellular brain and nerve tissue, the intellectual vitiation, the feeble morale may lie dormant for a life time, unless quickened by the interposition of an internal or external exciting cause., 13

In the early 1900s, the Society was much occupied with the debate on the issue of the inheritability of acquired characteristics, the Lamarckian position which was disputed by August Weismann and by his English disciple G. Archdall Reid. Reid argued against legislative intervention, since alcohol was a significant factor in the elimination of 'the unfit'. ${ }^{14}$ 
As this debate on heredity, its nature and the implications for state involvement continued, the language used in the Society's journal underwent something of a change. While discussions of inebriety continued to be dominant, the language of 'alcoholism' also began to be used. Inebriety had combined both drink and drugs in their liquid form (as for example laudanum), but injected drugs had never been part of the inebriates legislation of the late nineteenth century, although attempts were made to include drugs administered in this way under that broad umbrella. But the rise of 'alcoholism' as a separate condition meant that something initially termed rather vaguely in relation to drugs also began to make an appearance. In 1892, for example, Dr J.B. Mattison, an American expert, spoke to the Society about the treatment of the 'Morphine Disease'. The language here was quite different, even to the discussion of heredity as 'genetic' influences. The nature of treatment was also, with hindsight, interesting.

'Having secured the desired sedation, and reached the last day of opiate- using, it is our practice to give, at or before bedtime of that day, a full dose of morphine. This secures a sound, all-night sleep, from which the patient wakes most refreshed and often quite surprised at his good condition, which usually persists during the day. Towards evening-...some reflex symptoms may be expected, which are met with 20 grains of quinine, followed by half ounce doses of fluid extract of coca every second hour. Some cases require nothing else. If this fails, we give full doses of fluid extract of cannabis indica every two hours.' 15

Cannabis, chloral or sulphonal were used to bring sleep, but long term after care was important: relapse was an ever-present problem.

'That the management of these cases subsequent to the need of active medical care is of great importance, enlarged experience increasingly convinces. Neurotic or other disorders noted prior to addiction, whether genetic or not, must be relieved or removed... ${ }^{16}$ 
Increasingly, the duality of inebriety (combining alcohol and drugs) began to be used alongside this other, more 'modern' language. 'Alcoholism' made its appearance. In the early 1900s the term was caught up in the eugenic debate on national deterioration, focussed specifically on the role of women as mothers. Alcohol was one of the race poisons. C.W. Saleeby, talking about alcoholism and eugenics in 1909, commented that in the case of alcohol,

'The race or germ plasm is most resistant, the developing individual is least resistant, and the adult individual-that is to say, the mother- occupies an intermediate position in this respect.' 17

In 1910, Dr Bulkeley Hyslop, President of the Society and physician at Bethlem hospital, gave his Presidential address on 'the Study of Alcoholism' with suggestions for marriage restrictions for those who were biologically unfit or addicted to alcohol. ${ }^{18}$ Francis Hare, superintendent of the Norwood asylum, also in 1910, distinguished different forms of alcoholisms and also between those and morphinism. The alcoholic habit was of two kinds continuous (chronic alcoholism) and intermittent (dipsomania). The morphine habit on the other hand, was nearly always continuous (chronic morphinism). ${ }^{19}$

What could be seen in these pre war years was a strong connection between the concept of alcoholism and the eugenic debate in the pages of the Society's journal. Alcohol was spoken of alongside other 'race poisons' like tuberculosis and venereal disease. During the War, however, with the establishment of the Central Control Board (CCB) and its raft of controls on alcohol, a different type of language was also observable in relation to the substance. It was the language of control and of regulation. Alcohol was a 'social problem' rather than a 'disease'. Even those who held to some of the older pre war tenets, modified their views of what the post war world would hold for alcoholism or inebriety. Mary Scharlieb, a distinguished female physician, gave the eighth Norman Kerr memorial lecture in 1920 in the 
Robert Barnes Hall of the Royal Society of Medicine. The subject was 'The relation of Alcohol and Alcoholism to Maternity and Child Welfare', a traditional pre war subject but one where Scharlieb had modified her views. She traced the effects of alcohol on the unborn child, especially during the sperm or germ stages; the effect on breast feeding (the daughters of alcoholic parents were unable to suckle children). Alcohol and syphilis combined were thought to be responsible for the existence of epilepsy in $15 \%$ of the children of alcoholic parents. Alcoholism also brought to the fore the impact of 'efficiency' in the case of women who had a particular tendency to relapse.

So far the text of the lecture with its focus on women as culpable in their role as mothers, on the issue of inheritance and family responsibility, was traditional in its focus. Only the mention of efficiency (in the workplace) brought a tinge of the wartime ethos of the CCB. But when Scharlieb came to consider what might happen now the war was over, the agenda had significantly changed from the pre war one. The pre war situation could not be re established.

'The high rate of convictions for drunkenness and of mortality due directly to alcoholism, the awful loss of infant life, both ante and post-natal, the scourge of syphilis, the blight of inefficiency and of feeble mindedness, are but a few outstanding results of our pre war addiction to drink.'

After the war 'a contented, sober and efficient population' should be aimed at but one which was totally abstinent would not be possible. Scharlieb felt that the role of the medical profession should be to lead public opinion, and she placed emphasis on good housing and good food, amusements and care of the body. Lord D'Abernon, head of the CCB, had planned for regulation of the sale of drink in order to ensure the sobriety of the population. The issue of price was also important so that a 'due relation' was maintained between the 
price of alcohol and that of the prime necessities. Scharlieb wanted legislation which would cover hours of sale, dilution of alcohol, the reduction of licensed remises, provision for remedial not punitive treatment. Pubs should become public restaurants. ${ }^{20}$

Scharlieb's lecture underlined how the pre war scientific and policy agenda advanced by the medical inebriety specialists could no longer be maintained after the war. The alcohol issue had become a social question even for medical specialists; the acceptance of regulation rather than prohibition and the possibility of sobriety rather than abstinence underlined the change.

Meanwhile 'addiction', which Sir William Collins, President of the Society at the end of the war and one of the delegates representing the UK at the international opium conferences, called a 'new word' began to be used to categorise drugs, not alcohol. ${ }^{21}$ The word was of course not new and had long been used in a non-medical sense. But in the period around the First World War it became associated with novel tendencies in the field of drugs and alcohol. It was seen, as the Collins quotation implies, as a more modern term which did not carry with it the baggage of the older 'inebriety' with its hereditarian and temperance overtones. It fitted the new world of internationalism and drug specific controls. Sir William Willcox, adviser to the Home Office, and a member of the Rolleston committee on morphine and heroin addiction in the mid 1920s, gave the tenth Kerr lecture in 1924 on 'Drug Addiction'. The vote of thanks was given by Sir Humphrey Rolleston and was seconded by Sir Malcolm Delevingne, assistant under secretary of state in the Home Office and British representative on the Advisory committee of the League of Nations on the traffic in opium and dangerous drugs. Willcox's language underlined the new post war world of disease. The 'psychoneurotic factor' played a large part in drug addiction, now seen as an overall entity rather than substance specific as in 'morphine disease'. Addiction was at first a vice but after a month or so, a true disease became established with a definite pathology. There would be a 
low plane of physical health, and the mental symptoms were weakness of character and will and lack of a moral sense. However, some individuals managed well.

'In some cases, a drug addict may show even to an experienced observer few, if any, abnormal signs. The opium or morphine addict, if having his necessary allowance of the drug, may conduct himself normally from the oral and social point of view. And where the daily addiction amount is small, he may, for extensive periods, carry on his work in life. ${ }^{22}$

Here in essence was the problem confronted by the Rolleston committee in its hearings and report and which Rolleston himself and Delevingne, the Home Office civil servant were present to hear articulated. ${ }^{23}$

Based on a review of qualitative material from the specialist journal, the following conclusions can be derived. Firstly, there was a strong focus on inebriety as a concept from the 1880s until the first decade of the twentieth century, incorporating both drink and drugs (primarily the former) with an emphasis on heredity. Secondly, there was a rise of separate terminology, largely for alcohol-alcoholism, in the early decades of the twentieth century, connected with ideas about eugenics and race poison. Thirdly, the period saw the emergence of a new language of alcohol as social problem rather than disease during and after the war. Finally, we can also detect the rise of the language of addiction related to drugs, especially post World War One. Let us now look at what our quantitative research shows in relation to the overall conclusions of the qualitative work and the existing historiography outlined above.

\section{Quantitative research: methods}


Based on the qualitative research and previous work, a set of terms which could be used to denote disease-based understandings of drug and alcohol use were identified. These are listed in Table 1. As the research was part of the cross-national European study, the terminology and sources were selected with the aim of comparability in mind. We selected three sets of sources: a specialist journal dealing with the subject (the Proceedings of the Society for the Study of Inebriety/British Journal of Inebriety); two general medical journals (the British Medical Journal (BMJ) and The Lancet) and a standard medical textbook of the period. We did not select a specialist text on addiction because these, for example Norman Kerr's books on Inebriety, were UK and US specific, and for the cross-national component of the study we needed to select sources that would be as comparable as possible. The aim of using a general textbook was to see how 'addiction' was categorised for a general medical audience and how that perception changed over time. A set of searches were carried out using the terms. We identified, from the previous qualitative research, the period 1860-1930 as a significant one when changes in ideas about 'the disease' view of alcohol and drug use took place. In the UK, for example, a clear professional group was established in the 1870s-80s with the concept as its primary interest; and the War of 1914-18 and its aftermath led to legislative restrictions based on the notion of disease. The 1920s in the UK saw the medical profession and the Home Office establish a concordat around the concept of addiction. Alcohol restrictions were introduced during the First World War although alcohol subsequently dropped off the policy agenda. ${ }^{24}$

\section{$\underline{\text { Journals }}$}

All of the selected journals had been digitised, with searchable online archives and articles available as pdf. files. Yet, differing licensing agreements meant that only the $B M J$ was initially completely accessible this way. The British Journal of Inebriety required a user subscription, whilst full-text electronic access to the Lancet was only available onsite at two 
libraries. The BMJ and Lancet covered the whole time period 1860 to 1930 , but only post1904 search results could be obtained for the British Journal of Inebriety. The Society's early Proceedings were available as scanned (jpeg.) images, which prevented comparable electronic searches without the aid of text recognition software.

Digital sources presented some problems during the searches. For example, the default search option with some sources included all a publisher's titles rather than allowing a search within a specific time frame and journal. Moreover, it was not always possible to alter the chronological ordering of search results, in order to view 'oldest first'. This posed a particular challenge for terms which produced a large amount of results. Key-word searches within electronic articles were also inconsistent, and sometimes failed to capture terms within the text, especially when the file resolution was poor.

A third set of challenges concerned the nature of the search terms, with 'habit' being applied in many contexts, and thus generating false positives in the results. Furthermore, the inclusion of 'inebriety' in a journal name, and the widely-documented creation of the 'Society of the Study of Inebriety' (1884) both presented further difficulties, over emphasising the use of the term, and limited the search options for some sources and terms. Finally, certain words yielded insufficient data, which impeded attempts to chart their changing usage over time, or to make meaningful comparisons with how and when they were used in the other literature.

\section{$\underline{\text { Textbooks }}$}

The two general medical textbooks chosen were William Osler's The Principles and Practice of Medicine and Thomas Kirkpatrick Monro's Manual of Medicine. ${ }^{25}$ These titles were first published within the UK in 1892 and 1903 respectively, and went through multiple editions 
in the focal period. As mentioned above, these were chosen rather than a specialist addiction text which would not have been comparable cross-nationally. These sources were not digitised so a combination of index and chapter searches was used. It was often hard to obtain exact matches for the specified search terms, or, conversely, entries would simultaneously capture several concepts, such as through discussion of 'morphia habit'. Such variations and overlaps made it difficult to count accurately the number of uses of terms in any given edition, and meant that, instead of focusing on individual keywords, it was preferable to investigate stylistic or factual changes in the relevant paragraphs between editions of the textbook. The earliest textbook consulted was published in 1892, thereby preventing insights into how these concepts were discussed before this date. However, for both titles, the frequency of re-issue in the early twentieth century made it easier to pinpoint when any changes occurred, and facilitated comparison of content with contemporaneous sources. For these reasons there is no tabulation in this paper of terms used in the textbooks.

\section{Quantitative research: Results}

\section{Table 2: First and Total Usage of Key Terms, 1860-1930, BMJ and Lancet.}

Table 2 gives both first use and total overall use of our key terms in the $B M J$ and Lancet over the whole period. It shows that 'habit', 'chronic poisoning', 'addiction' and 'alcoholism' were in regular use in 1860 and afterwards, although the high figures recorded for these terms reflect their usage in varying contexts. References to 'inebriety' and 'dipsomania' began during the 1860s; 'morphinism' in the 1870s, and 'morphinomania' and 'narcomania' in the 1880s, and similar total uses of each term were found between the two titles. Patterns for the

British Journal of Inebriety were skewed due to the lack of pre-1904 content, and impeded by aforementioned difficulties in conducting searches and viewing results. To clarify, findings for a specified period were displayed amongst those from the publisher's other titles. For less 
common terms, it was possible to manually count the relevant citations, but 'habit', 'addiction', 'inebriety' and 'alcoholism' generated too many results for this to be practicable.

Table 3: First and Total Usage of Combined Terms, 1860-1930, BMJ and Lancet.

Table 3 shows the first and total use of combined terms, providing further indication of how more generic terms - such as 'habit' - were being applied. The results indicate that 'habit' and 'addiction' were both used much more often in the discussions of drugs, rather than alcohol, and this finding was consistent across both publications for this period. Similarities were also observed between the journals in dates of first use of 'alcohol habit', 'drug habit' and 'drug addiction'. However, with its earliest mention of 'alcohol addiction' in 1890, the $B M J$ preceded the Lancet by 25 years.

\section{Figure 1: Comparative annual uses of term 'inebriety', 1860-1930, BMJ and Lancet}

The term 'inebriety' was rarely mentioned in either the Lancet or BMJ until the early 1880 s. Thereafter, its usage rose sharply in the following decade, before declining circa 1900. In both journals, a second peak in use of this term occurred between 1905 and 1910, before another marked decline until 1918. Subsequently, until 1930, patterns of usage evened out in both journals, with annual uses of 'inebriety' ranging only from 3 to 11 cases in the $B M J$, and 4 to 15 cases in the Lancet. Inebriety as a term was clearly less popular as time went on.

\section{Figure 2: Comparative annual uses of term 'addiction', 1860-1930, BMJ and Lancet}

Between 1920 and 1930, both medical journals surveyed showed a rapid ascent in the use of the term 'addiction'; a pattern which was repeated in a further search for 'drug addiction' (fig. 4). 
It is clear, from figures 2 and 3 that the rise of 'addiction' as a term was connected with drugs and not with alcohol. In table 3 the use of the term addiction as applied to alcohol is quite limited, and overall, occurred just 6 times in the $B M J$ and 5 times in the Lancet, whereas 'drug addiction' was referenced on 64 and 107 occasions respectively within the same period.

\section{Figure 3: Comparative annual uses of term 'alcoholism', 1860-1930, BMJ and Lancet}

The two medical journals again showed very similar patterns in their discussions of 'alcoholism', peaking at 87 annual uses in 1901 (Lancet) and 1909 (BMJ). Between 1910 and 1918, rates dropped sharply, before rising slightly, and - unlike those of 'addiction' levelling somewhat thereafter.

Figure 4: Annual uses of term 'drug addiction', 1880-1930, BMJ and Lancet Figure 5: Annual uses of term 'drug habit', 1880-1930, BMJ and Lancet Likewise, a search for 'drug habit', whilst based on a small sample size, produced striking similarities between the $B M J$ and Lancet, in terms of frequency of use, date of first use, and clear predominance over mentions of 'alcohol habit'.

\section{Figure 6: Decadal Usage of Key Terms, 1860-1929, BMJ}

Figure 7: Decadal Usage of Key Terms, 1860-1929, Lancet

Figure 8: Five-Yearly Usage of Key Terms, 1900-1929, British Journal of Inebriety In addition to the previous trends observed for 'inebriety' and 'addiction', figures 6-8 show the ongoing, lesser, usage of a mix of other terminology in this era, namely, 'chronic poisoning', 'dipsomania', 'morphinism', 'morphinomania', and 'narcomania'. Figures 6-7 present decadal usage of the key terms for the $B M J$ and the Lancet, as annual use of these terms was small and fluctuated wildly between years, making the overall pattern difficult to determine. Figure 8 presents five-yearly usage of terms in the British Journal of Inebriety, as 
the period spanned (1860-1929) was shorter than for the other journals, allowing more data points to be plotted. Most terms showed a fairly even distribution over the whole period, but 'dipsomania' was used predominantly in the 1870s, 'morphinomania' and 'narcomania' only entered into the debate from the mid 1880s, and usage of 'chronic poisoning' peaked in the 1900s. Results from the British Journal of Inebriety (figure 8) necessarily cover a more limited period, but show continued use of all five terms into the early twentieth century, with 'dipsomania' being the most popular term, featuring a second sharp rise in use in the late 1920s.

\section{Discussion: bringing the qualitative and the quantitative together}

The way in which compulsive substance use is characterised and how this language changes over time is important. The terminology used represents the interests of changing groups of key interests and is a representation of changing power relationships within an evolving field. From extant qualitative research outlined above, we already have an idea of how theories of disease established themselves and in what form in this period. How did our digital and formalised searches add to this picture?

The digital searches showed very clearly the rise and predominance of the concept of inebriety in the medical arena from the 1870s. The establishment of the Society for the Study of Inebriety and its journal may have skewed the results for that journal search. But the significance of the term in the general medical journals underlines the rise of this term in medical discourse at the time. Further periods of extensive discussion came in the early 1900s, something that was to be expected given the widespread discussion of the extension of inebriates legislation at that time and concerns about national degeneration. The results show 
how inebriety fell out of favour around the time of the First World War and it was rarely used thereafter. So the quantitative research confirmed that a term which covered both drugs and alcohol, but with a focus on the latter, was falling out of favour.

The digital searches also showed that two terms began to replace the unified inebriety concept. Perhaps surprisingly, the sources show the rise of the separate term 'alcoholism' from the late nineteenth century (Figure 3). But, unlike 'addiction', this did not maintain its rise to prominence in the twentieth century but had declined in importance by 1914 . The more 'modern' term did not achieve acceptability in the way in which drug addiction did. This may be related to the decline in interest in alcohol as an issue after World War One. The qualitative research provides some clues here, in that discussion of alcohol as a social problem with the need for measures of local regulation, and the use of price mechanisms, had emerged after the work of the CCB during the war. The decline of this more medical terminology also throws new light on the 'rediscovery' of the disease of alcohol after World War Two - the earlier use of the terminology was largely forgotten.

The rise of the term 'addiction' is also clearly displayed from around 1918. But here came a significant divergence. Inebriety was a term which had encompassed alcohol and drugs within the same framing; it applied to both substances with a particular emphasis on alcohol. Addiction, however, was not a combined term and the association between 'addiction' and 'drug' is clearly demonstrated in the figures. The term 'habit' was also more closely associated with 'drug' than with 'alcohol'. So we can see the beginnings of the clear divergence in theories and concepts which occupied the inter- and immediate post Second World War period. The declining significance of the alcohol related terms may also relate to alcohol's own demise as a policy issue after 1918. The gradual decline of 'inebriety' and the ascent of 'addiction' within journals, occurred against a backdrop of continued occasional use of a mix of other terms, and common interchange of, for example, 'morphinism', 'morphine 
habit', or 'morphinomania' within the medical texts surveyed. This was clearly a period of flux in the development of an agreed terminology but the general trends - the rise and decline of 'inebriety' and the rise of 'addiction' focussed on drugs - are clear.

\section{Conclusion}

The use of digital and standardised search methodology and terms illuminates the debate in this period about how to conceptualise a disease-based view of drug and alcohol use. It identifies the rise and decline of 'inebriety' and of 'alcoholism' and the emergence of 'addiction' as a 'modern' term out of a welter of other possibilities. Its use in conjunction with the more specific qualitative research (which was carried out through non- digital methods) confirms and deepens the initial conclusions. It also enables such conclusions to be based more quickly on a greater volume of research material. It has highlighted conclusions about alcohol and alcoholism which might not have emerged so strongly from qualitative only research.

Adopting such a dual methodology also enables conclusions to be drawn about the potential and the limitations of digital search methods. ${ }^{26}$ Historians are beginning to discuss the implications of the digitisation of historical research materials and to assess what is gained and what lost through the process. The historian Tim Hitchcock, for example, has recently drawn attention to the 'unappetizing smorgasbord of meta data standards' applied to historical research materials online which makes their discovery in any context 'an information turkey shoot of dubious value'. ${ }^{27}$ Bob Nicholson takes a more positive view; discussing how new methodologies could develop in relation to digital research on newspapers. ${ }^{28}$

How do our results contribute to this wider debate? These allow for fine-grained content analysis which in the past would have been time consuming and laborious. They give a clear 
picture of the rise and fall of terms over time which could be combined with further qualitative research to explore how and why these terms were used. Technical issues often prevent the easy searching which at first seems to be possible; platforms providing digital access to journals need to bear this type of historical research in mind and to be configured in a way which makes it possible. As Hitchcock has argued, historians themselves need to be more involved in the ways in which the research data is being digitally configured for us. 


\begin{tabular}{|c|c|c|}
\hline HABIT & DIPSOMANIA & ALCOHOLISM \\
\hline CHRONIC POISONING & MORPHINOMANIA & NARCOMANIA \\
\hline INEBRIETY & MORPHINISM & ADDICTION \\
\hline
\end{tabular}

Table 1: Key Search Terms

\begin{tabular}{|c|c|c|c|}
\hline Term & Publication & First Usage & Total Uses, 1860-1930 \\
\hline \multirow{2}{*}{ Habit } & Lancet & Jan 1860 & 14,400 \\
\hline & $B M J$ & Jan 1860 & 12,071 \\
\hline \multirow[t]{3}{*}{ Chronic poisoning } & Lancet & June 1860 & 190 \\
\hline & $B M J$ & March 1860 & 143 \\
\hline & British J. Inebriety & Oct 1904 & 10 \\
\hline \multirow[t]{2}{*}{ Inebriety } & Lancet & Jan 1860 & 726 \\
\hline & $B M J$ & March 1863 & 752 \\
\hline \multirow[t]{3}{*}{ Morphinism } & Lancet & Dec 1875 & 88 \\
\hline & $B M J$ & Dec 1877 & 82 \\
\hline & British J. Inebriety & July 1905 & 23 \\
\hline \multirow[t]{3}{*}{ Morphinomania } & Lancet & April 1887 & 44 \\
\hline & $B M J$ & March 1886 & 59 \\
\hline & British J. Inebriety & April 1904 & 6 \\
\hline \multirow[t]{3}{*}{ Dipsomania } & Lancet & June 1861 & 153 \\
\hline & $B M J$ & Oct 1860 & 163 \\
\hline & British J. Inebriety & April 1904 & 57 \\
\hline \multirow[t]{3}{*}{ Narcomania } & Lancet & July 1887 & 17 \\
\hline & $B M J$ & July 1887 & 37 \\
\hline & British J. Inebriety & July 1905 & 10 \\
\hline \multirow[t]{2}{*}{ Addiction } & Lancet & March 1860 & 250 \\
\hline & $B M J$ & Feb 1861 & 372 \\
\hline \multirow[t]{2}{*}{ Alcoholism } & Lancet & Jan 1860 & 2,335 \\
\hline & $B M J$ & Jan 1860 & 2,096 \\
\hline
\end{tabular}

Table 2: First and Total Usage of Key Terms, BMJ and Lancet, 1860-1930

\begin{tabular}{|l|l|l|l|}
\hline Search Term & Publication & First Usage & Total Uses, 1860-1930 \\
\hline \multirow{2}{*}{ "Alcohol habit" } & Lancet & June 1888 & 16 \\
\cline { 2 - 4 } & BMJ & June 1884 & 12 \\
\hline \multirow{2}{*}{ "Drug habit" } & Lancet & Aug 1895 & 175 \\
\cline { 2 - 4 } & BMJ & Jan 1897 & 106 \\
\hline \multirow{2}{*}{ "Alcohol addiction" } & Lancet & Oct 1915 & 5 \\
\cline { 2 - 4 } & BMJ & Sept 1890 & 6 \\
\hline "Drug addiction" & Lancet & Sept 1900 & 107 \\
\hline
\end{tabular}


64

Table 3: First and Total Usage of Combined Terms, BMJ and Lancet, 1860-1930

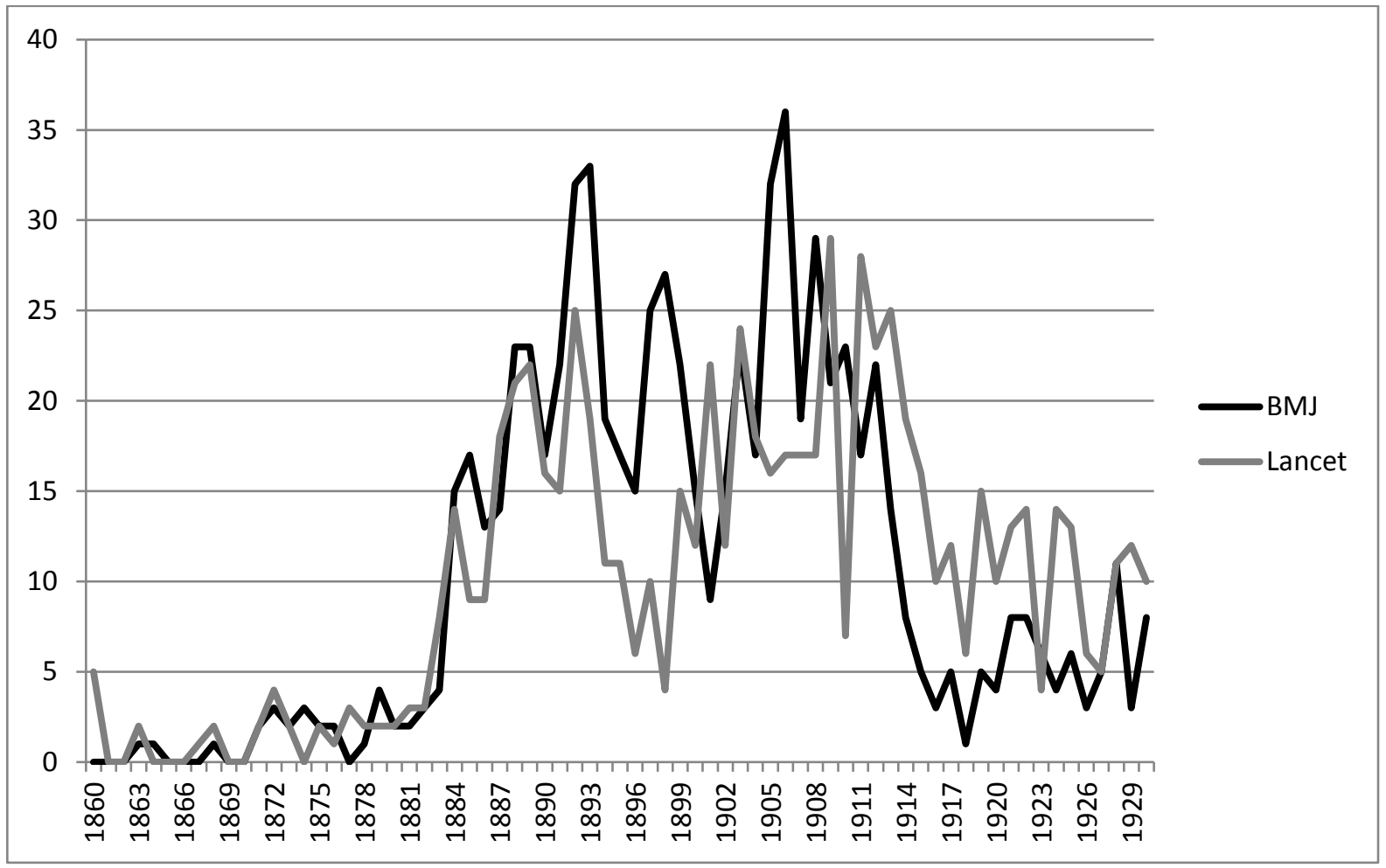

Figure 1: Comparative annual uses of term 'inebriety', 1860-1930, BMJ and Lancet 


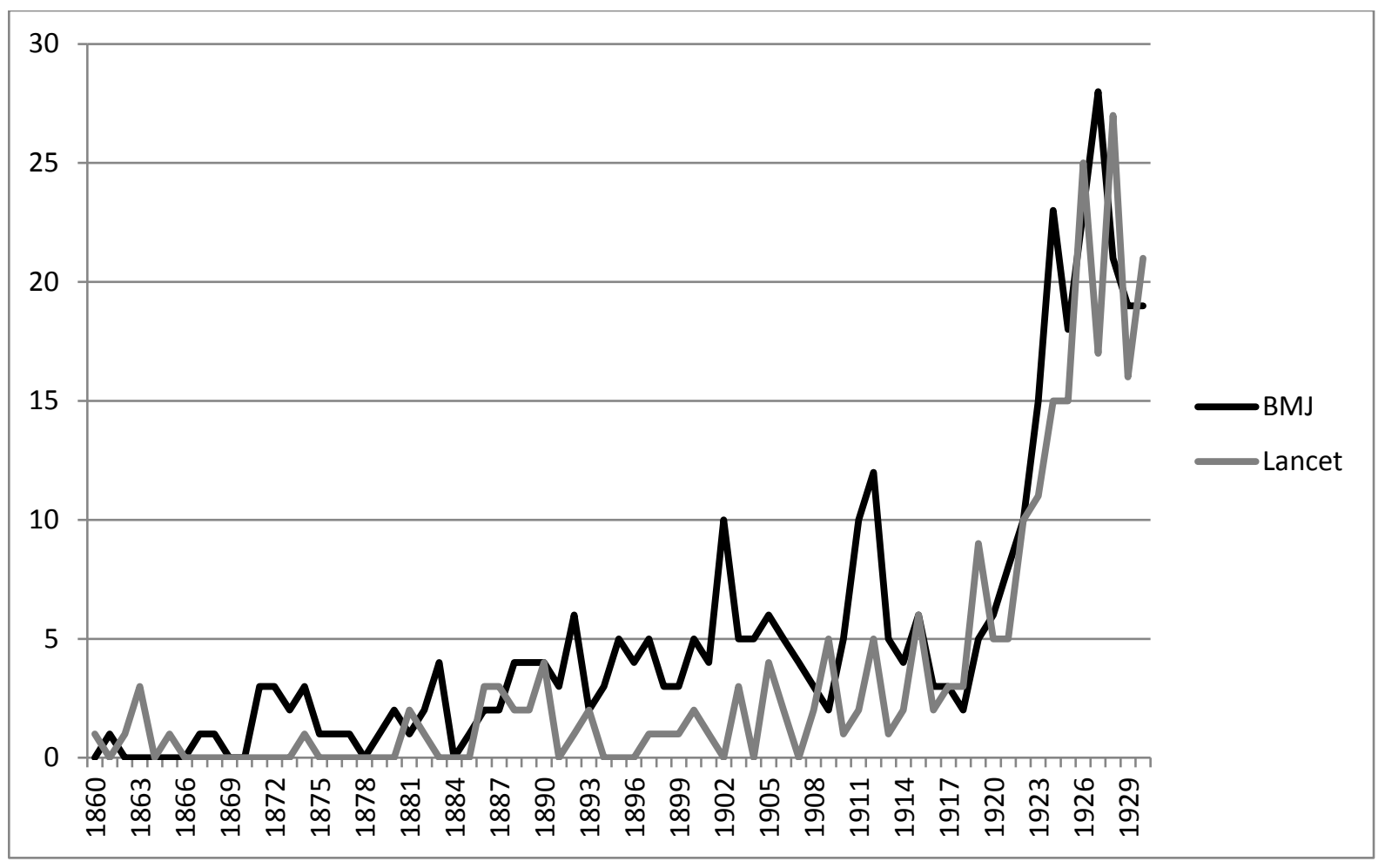

Figure 2: Comparative annual uses of term 'addiction', 1860-1930, BMJ and Lancet 


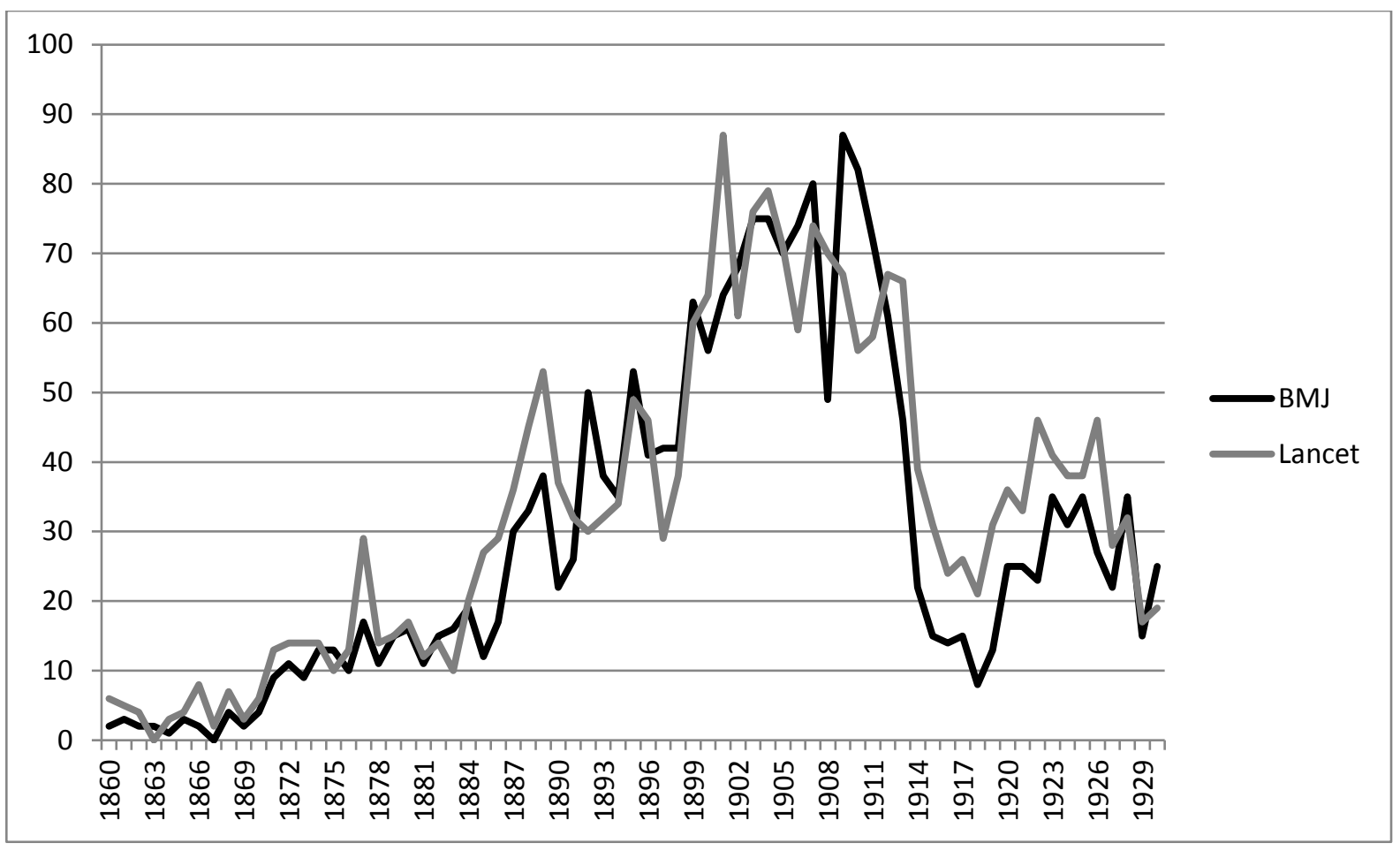

Figure 3: Comparative annual uses of term 'alcoholism', 1860-1930, BMJ and Lancet

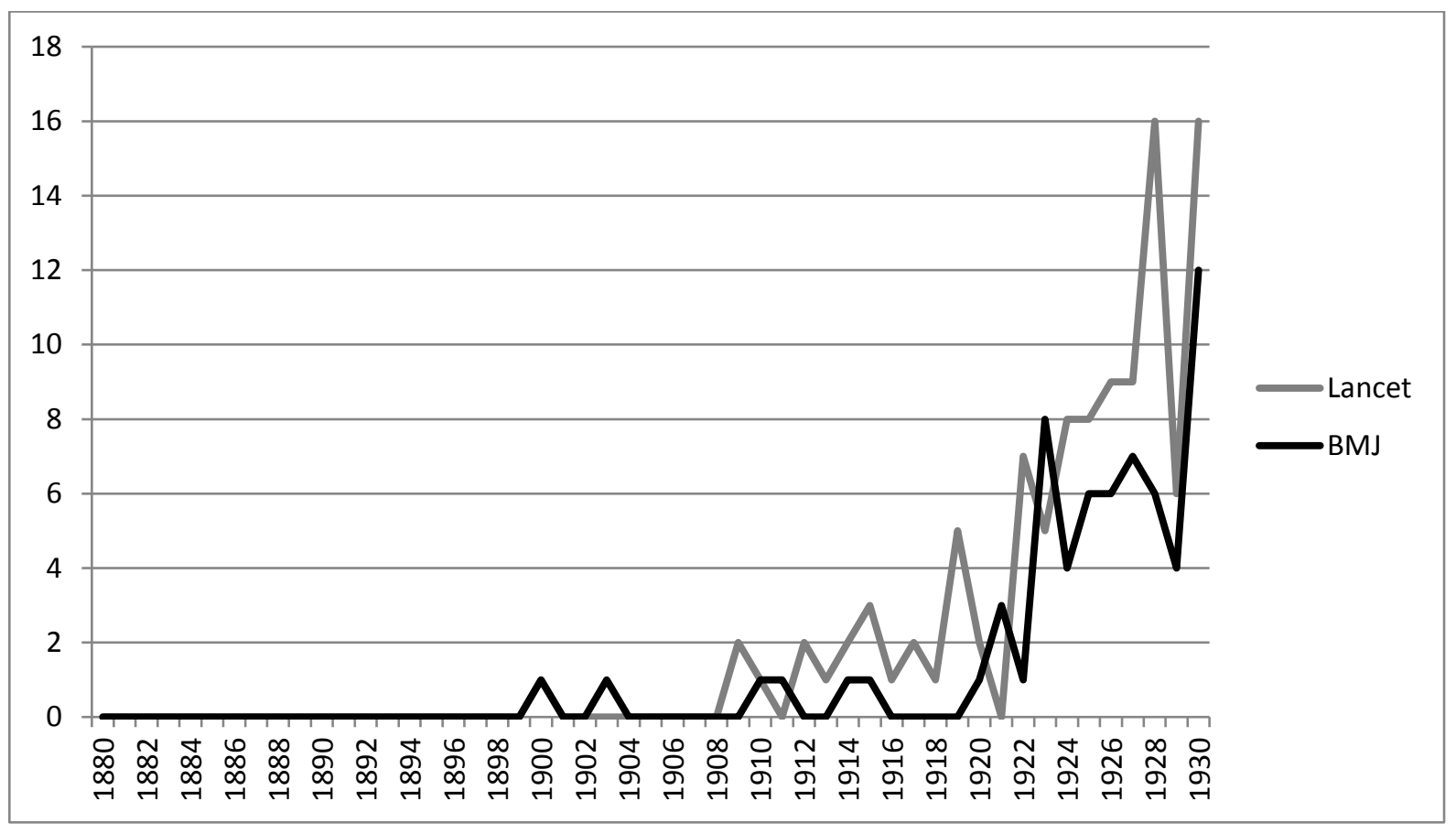

Figure 4: Annual uses of term 'drug addiction', 1880-1930, BMJ and Lancet 


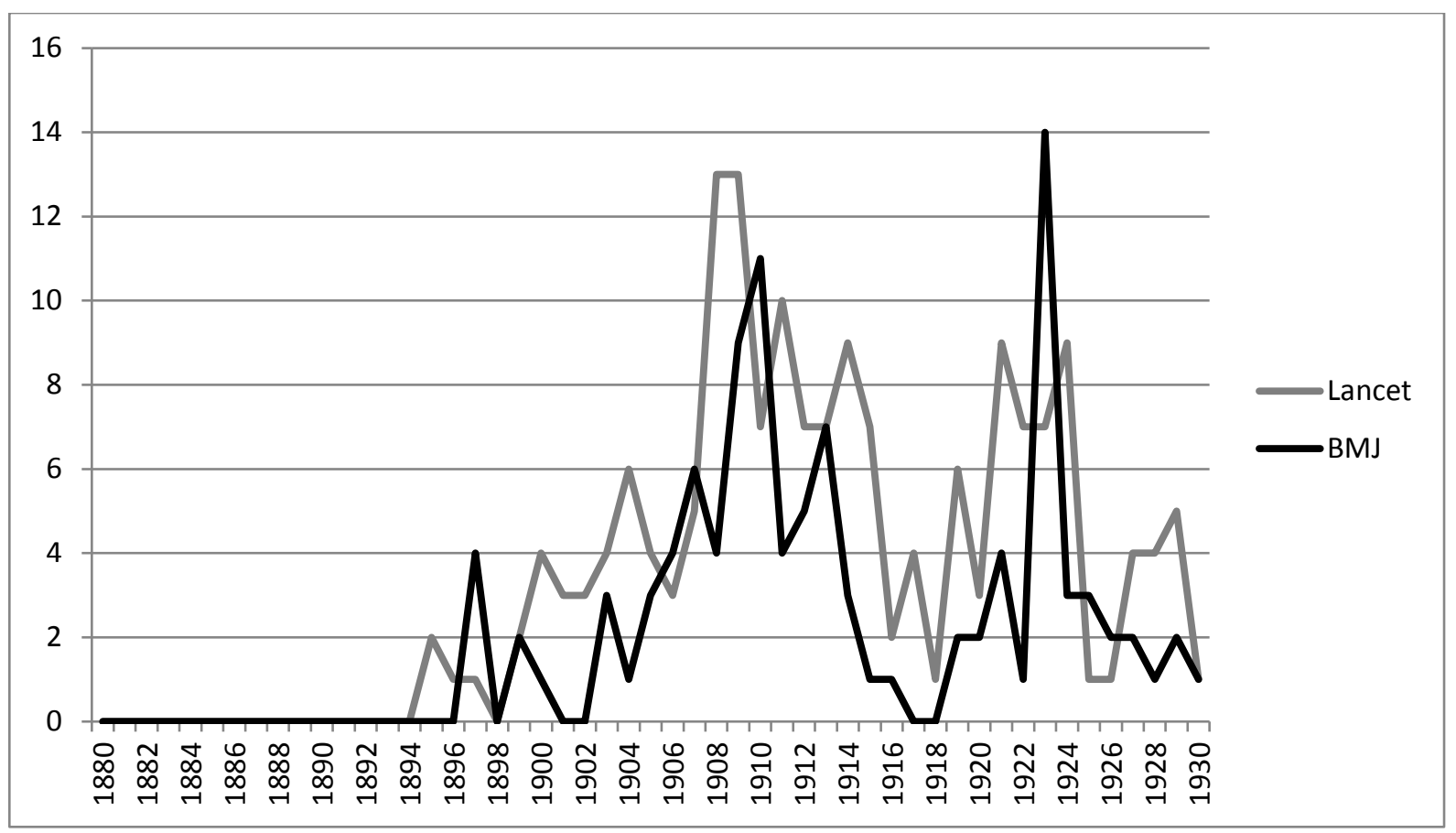

Figure 5: Annual uses of term 'drug habit', 1880-1930, BMJ and Lancet

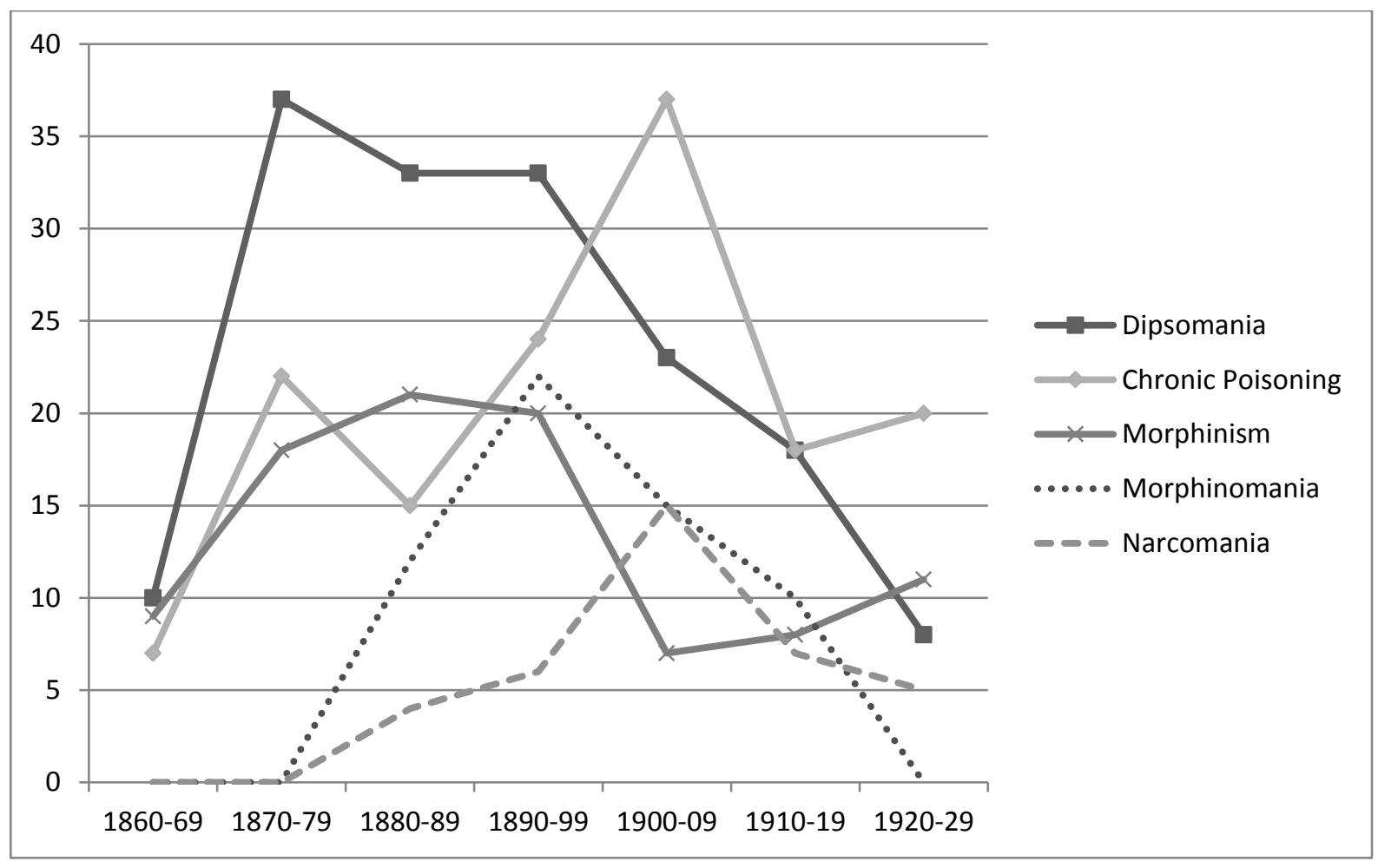

Figure 6: Decadal Usage of Key Terms, 1860-1929, BMJ 


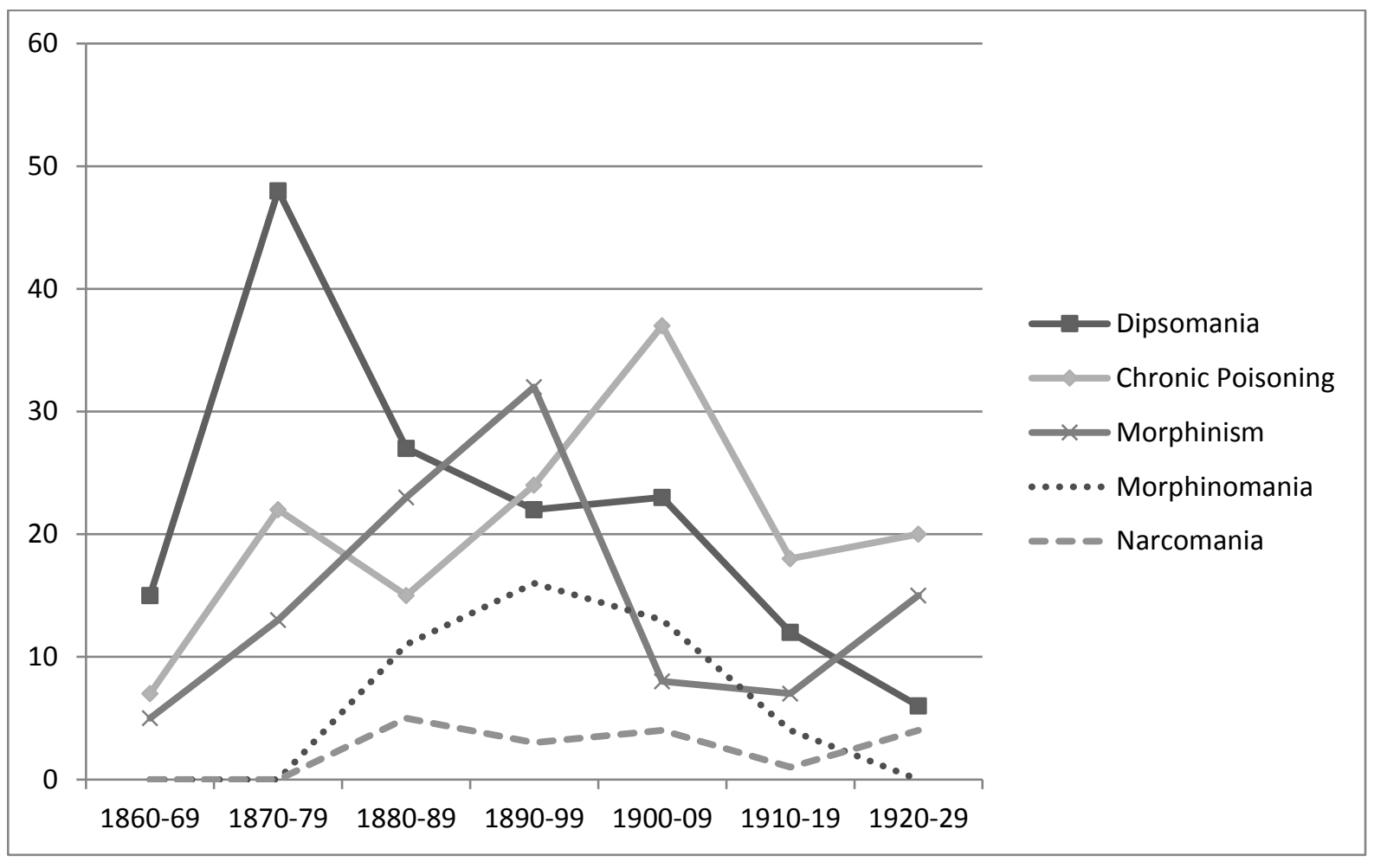

Figure 7: Decadal Usage of Key Terms, 1860-1929, Lancet 


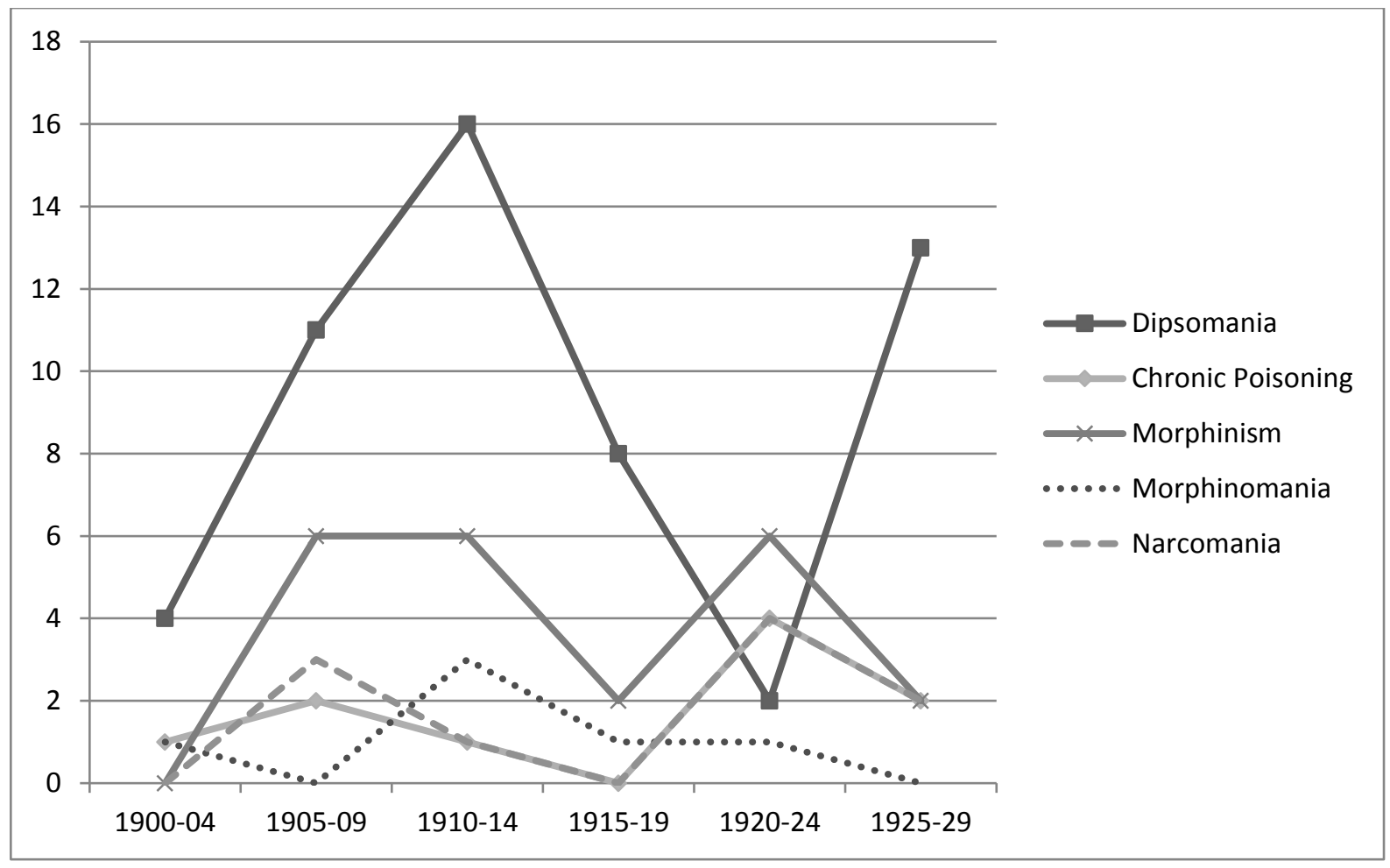

Figure 8: Five-Yearly Usage of Key Terms, 1900-1929, British Journal of Inebriety 
${ }^{1}$ H. Levine, 'The Discovery of Addiction. Changing Conceptions of Habitual Drunkenness in America', Journal of Studies on Alcohol 39(1) (1978) 143-74; V. Berridge, Opium and the People. Opiate Use and Drug Control Policy in nineteenth and early twentieth century England (London: Free Association Books, 1999) revised edition; M. Valverde, Diseases of the Will. Alcohol and the Dilemmas of Freedom (Cambridge: Cambridge UP, 1998).

${ }^{2}$ Levine, 'Discovery of Addiction'op.cit

${ }^{3}$ R. Porter, 'The drinking man's disease: the pre-history of alcoholism in Georgian Britain', British Journal of Addiction, 80(1985), 385-96.

${ }^{4}$ V. Berridge,'The Society for the Study of Addiction, 1884-1988' special issue of British Journal of Addiction, 85(8) (1990), 983-1087.

${ }^{5} \mathrm{~W}$. Bynum, 'Chronic alcoholism in the first half of the nineteenth century' Bulletin of the History of Medicine, 42 (1968), 160-85.

${ }^{6}$ E. Levinstein, Morbid Craving for Morphia (Die Morphiumsucht) (London :Smith,Elder, 1878)

${ }^{7}$ T.C. Allbutt, A System of Medicine (London : Macmillan,1897).

${ }^{8}$ T. Hickman, The Secret Leprosy of Modern Days (Amherst: University of Massachusetts Press, 2007).

${ }^{9}$ Discussion at a meeting of the Society for the Study of Inebriety 1 July 1884, Proceedings of the Society for the Study of Inebriety (1) (1884), 38.

${ }^{10}$ Discussion at meeting of Society for the Study of Inebriety, Proceedings of Society for the Study of Inebriety $1,1884,41$ 
${ }^{11}$ Ordinary meeting of the Society, October, 1884 , Proceedings of the Society for the Study of Inebriety 2( 1884), 3

${ }^{12}$ Reception at the Dalrymple Home for Dr. Joseph Parrish in November, 1885 ,Proceedings of the Society for the Study of Inebriety 6 (1885),1

${ }^{13}$ Presidential address, Proceedings of the Society for the Study of Inebriety 12( 1887-9),6-9

${ }^{14}$ Berridge, Society for the Study of Addiction, 1001, 1012.

15 J. B. Mattison, 'The Treatment of the Morphine Disease', Proceedings of the Society for the Study of Inebriety, 32 (1892-4).1-16

${ }^{16}$ Mattison, 13.

${ }^{17}$ C.W.Saleeby, 'Alcoholism and Eugenics', British Journal of Inebriety 7 (1909-10),7-20.

${ }^{18}$ T. B. Hyslop, 'The Study of Alcoholism' British Journal of Inebriety 1, (1910-11) ,1-5

${ }^{19}$ F. Hare, 'The Withdrawal of Narcotics from Habitues' British Journal of Inebriety 2 (1910-11), 86-90.

${ }^{20}$ M. Scharlieb, 'The Relation of Alcohol and Alcoholism to Maternity and Child Welfare,' British Journal of Inebriety 3(1919-20), 91-139.

${ }^{21}$ Sir W. J. Collins, 'Drinks and Drugs of Addiction' British Journal of Inebriety, 4 (1919), 85-89.

${ }^{22}$ W. Willcox, 'Drug Addiction’ British Journal of Inebriety 3(1924),75-97.

${ }^{23}$ V. Berridge, Opium and the People, 264-78.

${ }^{24}$ V. Berridge, op. cit.; J. Nicholls, The Politics of Alcohol: A History of the Drink Question in England (Manchester: Manchester University Press, 2009) 
${ }^{25} \mathrm{~W}$. Osler, The Principles and Practice of Medicine: Designed for the Use of Practitioners and Students of Medicine, $1^{\text {st }}$ edition (Edinburgh, London: Young J. Pentland, 1892); T.K. Monro, Manual of Medicine, 1st edition (London: Bailliere, Tindall and Cox, 1903).

${ }^{26}$ V. Berridge, 'Digitising and democratising historical research' Addiction, 101(2006), 1533 35.

${ }^{27}$ T. Hitchcock, 'Confronting the Digital: Or, How Academic History Writing Lost the Plot', Cultural and Social History 10,1 (2013), 9-23.

${ }^{28}$ B. Nicholson, 'The Digital Turn: Exploring the methodological possibilities of digital newspaper archives,' Media History 19,1(2013),59-73. 